\title{
Prevalence of the metabolic syndrome in patients with schizophrenia treated with antipsychotic medication
}

\author{
Marc A. De Hert ${ }^{\text {a }}$, Ruud van Winkel ${ }^{\mathrm{a}}$, Dominique Van Eyck ${ }^{\mathrm{a}}$, Linda Hanssens ${ }^{\mathrm{b}}$, Martien Wampers ${ }^{\mathrm{a}}$, Andre \\ Scheen ${ }^{c}$, Joseph Peuskens ${ }^{\text {a }}$ \\ ${ }^{\mathrm{a}}$ University Center St Jozef, Catholic University Louvain, Leuvense Steenweg 517, 3070 Kortenberg, Belgium ${ }^{\mathrm{b}}$ \\ Department of Epidemiology and Public Health, University Liege, Belgium ${ }^{c}$ Department of Diabetology, CHU \\ de Sart Tilman, University Liege, Belgium
}

\begin{abstract}
The presence of the metabolic syndrome is an important risk factor for cardiovascular disease and diabetes. There are limited data on the prevalence of the metabolic syndrome in European patients suffering from schizophrenia.
\end{abstract}

Methods: All consecutive patients with schizophrenia at our university psychiatric hospital and affiliate services were entered in an extensive prospective metabolic study including an oral glucose tolerance test. The prevalence of the metabolic syndrome was assessed based on the National Cholesterol Education Program criteria (NCEP, Adult Treatment Protocol, ATP-III), adapted ATP-III criteria using a fasting glucose threshold of $100 \mathrm{mg} / \mathrm{dl}$ (AHA) and on the recently proposed criteria from the International Diabetes Federation (IDF).

Results: The analysis of 430 patients showed a prevalence of the metabolic syndrome of $28.4 \%$ (ATP-III), $32.3 \%$ (ATP-III A) and 36\%) (IDF), respectively. The prevalence of the metabolic syndrome in our sample of patients with schizophrenia is at least twice as high compared to an age-adjusted community sample in Belgium.

Conclusion: The metabolic syndrome is highly prevalent among treated patients with schizophrenia. It represents an important risk for cardiovascular and metabolic disorders. Assessment of the presence and monitoring of the associated risks of the metabolic syndrome should be part of the clinical management of patients treated with antipsychotics.

Keywords: Schizophrenia; Metabolic syndrome; Physical health

\section{INTRODUCTION}

Metabolic abnormalities have consistently been identified as a part of schizophrenic illness (Allison et al., 1999; Homel et al., 2002; Meduna et al., 1942; Raphael, 1921). The interest in this topic has recently been renewed since the introduction of second generation antipsychotics and their possible association with metabolic abnormalities (Allison and Casey, 2001; Jin et al., 2004; Meyer and Koro, 2004). The issue of abnormalities in glucose metabolism, in particular diabetes mellitus (DM), has hereby received most attention (De Nayer et al., 2005; Haupt and Newcomer, 2001; Jin et al., 2002, 2004; Newcomer, 2005; Scheen and De Hert, 2005).

However, other conditions such as cardiovascular morbidity, abnormal lipid metabolism and obesity also have a serious impact on the physical health of patients diagnosed with schizophrenia. The importance of diagnosing and treating these medical conditions needs to be stressed. Not only is the presence of these conditions associated with a excess mortality rate because of elevated cardiovascular risk (Brown, 1997; Brown et al., 2000; Osby et al, 2000a,b), it has also been associated with a lower functional outcome (Lyketsos et al, 2002), a higher prevalence of psychotic and depressive symptoms (Dixon et al., 1999), a worse perceived physical health (Dixon et al., 1999; Meyer et al, 2005) and lower adherence to medication (Robinson et al., 2002; Weiden et al, 2004).

Therefore, researchers have developed a growing interest in the Metabolic Syndrome (MetS), which comprises abnormalities in glucose metabolism, lipid metabolism, obesity and blood pressure. The most commonly used 
definitions for the Metabolic Syndrome are the Adult Treatment Protocol (ATP-III) of the National Cholesterol Education Program (NCEP) (Expert Panel on Detection and Evaluation of Treatment of High Blood Cholesterol in Adults, 2001), and the adapted ATP-III A proposed by the AHA following the ADA lowering of the threshold for impaired fasting glucose to $100 \mathrm{mg} / \mathrm{dl}$ (Expert Committee on the Diagnosis and Classification of Diabetes Mellitus, 2003; Grundy et al., 2004). A more recent definition, by the International Diabetes Federation (IDF, 2005), stressed the importance of waist circumference, using both more stringent and ethnic-/race-specific criteria. Recent research on MetS in the general population has indeed provided evidence for the development of ethnic-/race-specific criteria (Cossrow and Falkner, 2004; Ford et al., 2002; Park et al., 2003; Kraja et al., 2005; Misra et al, 2005; Rakugi and Ogihara, 2005). Until now, it has remained unclear to what extent these differences in the general population are due to genetic factors or cultural factors such as life style or economic factors

To evaluate the prevalence of MetS in patients diagnosed with schizophrenia and the impact of life style and economic factors within distinct ethnic groups, prospective large sample studies in different countries are needed. Only few studies on the prevalence of MetS among patients diagnosed with schizophrenia are available. The prevalence of MetS in these studies was around 40\% (Basu et al., 2004; Heiskanen et al, 2003), but limited conclusions can be drawn from these studies because of their limited sample sizes. A large study by Cohn et al. of 240 Canadian subjects revealed a prevalence rate of $42.6 \%$ for males and $48.5 \%$ for females (Cohn et al., 2004). These figures are comparable to those found in the CATIE study by McEvoy et al. who found prevalence rates of 36.6\% for males and 54.2\% for females (McEvoy et al., 2005). To our knowledge, this is the first large sample European study on the prevalence of MetS. In a preliminary report, a prevalence rate of $22 \%$ among a sample of 100 patients was found (De Hert et al., in press). We therefore hypothesized that the prevalence rate of MetS for our sample of 430 schizophrenic subjects would be lower than the US and Canadian prevalence rates found by McEvoy et al. and Cohn et al., respectively.

\section{METHODS}

All consecutive patients with a DSM-IV diagnosis of schizophrenia or schizoaffective disorders (18.6\%), both out- $(28.4 \%)$ or in-patients, of a university psychiatric hospital and affiliate services, were asked to participate in an extensive screening and prospective follow-up study of metabolic parameters. The prospective inclusions started in November 2003. At baseline, patients received a full-fasting laboratory screening, clinical measurements and an ECG. A 75-g glucose load Oral Glucose Tolerance Test (OGTT) was performed in a large subsample of patients. Patients were initiated on an overnight fast and were monitored during the OGTT. All laboratory analyses were performed in the same laboratory.

Table 1-Definitions of the metabolic syndrome

\begin{tabular}{llll}
\hline Criteria & ATP-III $^{\mathrm{a}}$ & ATP-III A $^{\mathrm{a}}$ & IDF $^{\mathrm{b}}$ \\
\hline Waist $(\mathrm{cm})$ & $\mathrm{M}>102$, & $\mathrm{M}>102$, & $\mathrm{M} \geq 94$, \\
& $\mathrm{F}>88$ & $\mathrm{~F}>88$ & $\mathrm{~F} \geq 80$ \\
& & & Obligatory \\
& & & criterion \\
& $\geq 130 / 85$ & $\geq 130 / 85$ & $\geq 130 / 85$ \\
$\mathrm{BP}^{\mathrm{C}}$ & $\mathrm{M}<40$, & $\mathrm{M}<40$, & $\mathrm{M}<40$, \\
$\mathrm{HDL}(\mathrm{mg} / \mathrm{dl})$ & $\mathrm{F}<50$ & $\mathrm{~F}<50$ & $\mathrm{~F}<50$ \\
& $\geq 150$ & $\geq 150$ & $\geq 150$ \\
TG $(\geq 150 \mathrm{mg} / \mathrm{dl})$ & $\geq 110$ & $\geq 100$ & $\geq 100$ \\
Glucose $(\mathrm{mg} / \mathrm{dl})^{\mathrm{d}}$ & & &
\end{tabular}

${ }^{a}$ MetS if 3 of 5 criteria are met

${ }^{\mathrm{b}}$ MetS if additional 2 criteria are met (waist is obligatory).

${ }^{\mathrm{d}} \mathrm{Or}$ if treated with antihypertensive medication. Or if treated with insulin or hypoglycaemic medication.

The presence of the MetS was assessed using the ATP-III criteria, the adapted ATP-III criteria (AHA; fasting glucose $\geq 100 \mathrm{mg} / \mathrm{dl}$ ) and the recent IDF criteria. For the diagnosis of diabetes and pre diabetic abnormalities, we used the criteria of The American Diabetes Association [impaired fasting glucose (IFG) $\geq 100 \mathrm{mg} / \mathrm{dl}$ and impaired glucose tolerance (IGT), glucose $>140 \mathrm{mg} / \mathrm{dl}$ at $2 \mathrm{~h}$ in the OGTT] (Expert Committee, 1997, 2003).

Descriptive statistics were computed for the basic demographic and clinical variables as well as for the variables relevant for the evaluation of metabolic abnormalities. The influence of the presence/absence of the metabolic syndrome and the presence/absence of glucose abnormalities on continuous variables was assessed by means of an independent samples $t$-test. The association between categorical variables was evaluated by a Chi-square test 
(Table 1).

The study was approved by an ethical committee and all patients gave written informed consent.

\section{RESULTS}

The mean age of the patients was 36.5 years $($ S.D. $=11.8)$ and the mean duration of illness was 13.0 years $($ S.D. $=$ 10.1). $64.9 \%$ of the patients were male. $99 \%$ were white and Belgian natives. For 404 of 418 patients in our sample (excluding patients being treated for diabetes, $n=12$ ), an OGTT could be done at baseline. No significant differences in age or sex were found between the patients that were tested and that were not tested.

All patients were treated with antipsychotic medication. On average they received $3.2($ S.D. $=2.0)$ different medications. Antipsychotics were combined with anticholinergics (15.8\%), antidepressants (38.6\%), benzodiazepines (33.7\%), mood stabilisers (24.6\%) and somatic medication (43.2\%). 2.3\% (12 patients) was being treated for diabetes, $1.9 \%$ of patients took a statin ( 8 patients) and $10.5 \%$ (45 patients) took antihypertensive medication.

The majority of patients were treated with only one antipsychotic (87\%). $77.2 \%$ of this group received a secondgeneration antipsychotic, $9.8 \%$ a first-generation antipsychotic. The remaining patients took a combination of 2 antipsychotics. $8.1 \%$ combined a first- with a second-generation agent, $4.4 \%$ combined 2 second-generation drugs and $0.5 \%$ combined first-generation antipsychotics. The overall distribution of antipsychotics was: $16.7 \%$ first-generation antipsychotics; $6.6 \%$ amisulpride; $0.2 \%$ aripiprazole; $16.1 \%$ clozapine, $30.3 \%$ olanzapine, $11.7 \%$ quetiapine and $18.5 \%$ risperidone.

Table 2-Metabolic syndrome and criteria prevalence among all subjects

\begin{tabular}{|c|c|c|c|}
\hline Criteria & All & Male $(N=279)$ & Female $(N=151)$ \\
\hline MS ATP-III & $28.4 \%(122)$ & $28.0 \%(78)$ & $29.1 \%(44)$ \\
\hline Waist $(\mathrm{M}>102, \mathrm{~F}>88)$ & $37.4 \%(161)$ & $28.0 \%(78)$ & $55.0 \%(83)$ \\
\hline $\mathrm{BP}(\geq 130 / 85)$ & $48.8 \%(210)$ & $49.8 \%(139)$ & $47.0 \%(71)$ \\
\hline HDL $(\mathrm{M}<40 \mathrm{mg} / \mathrm{dl}, \mathrm{F}<50 \mathrm{mg} / \mathrm{dl})$ & $29.8 \%(128)$ & $30.8 \%(86)$ & $27.8 \%(42)$ \\
\hline $\mathrm{TG}(\geq 150 \mathrm{mg} / \mathrm{dl})$ & $42.3 \%(182)$ & $45.5 \%(127)$ & $36.4 \%(55)$ \\
\hline Glucose $(\geq 110 \mathrm{mg} / \mathrm{dl})$ & $10.9 \%(47)$ & $9.7 \%(27)$ & $13.2 \%(20)$ \\
\hline MS ATP-III A (AHA) & $32.3 \%(139)$ & $30.5 \%(85)$ & $35.8 \%(54)$ \\
\hline Waist $(\mathrm{M}>102, \mathrm{~F}>88)$ & $37.4 \%(161)$ & $28.0 \%(78)$ & $55.0 \%(83)$ \\
\hline $\mathrm{BP}(\geq 130 / 85)$ & $48.8 \%(210)$ & $49.8 \%(139)$ & $47.0 \%(71)$ \\
\hline HDL $(\mathrm{M}<40 \mathrm{mg} / \mathrm{dl}, \mathrm{F}<50 \mathrm{mg} / \mathrm{dl})$ & $29.8 \%(128)$ & $30.8 \%(86)$ & $27.8 \%(42)$ \\
\hline $\mathrm{TG}(\geq 150 \mathrm{mg} / \mathrm{dl})$ & $42.3 \%(182)$ & $45.5 \%(127)$ & $36.4 \%(55)$ \\
\hline Glucose $(\geq 100 \mathrm{mg} / \mathrm{dl})$ & $25.3 \%(109)$ & $22.6 \%(63)$ & $30.5 \%(46)$ \\
\hline MS IDF & $36.0 \%(155)$ & $34.1 \%(95)$ & $39.7 \%(60)$ \\
\hline Waist ( $M \geq 94, F \geq 80)$ & $62.1 \%(267)$ & $55.5 \%(155)$ & $74.2 \%(112)$ \\
\hline $\mathrm{BP}(\geq 130 / 85)$ & $48.8 \%(210)$ & $49.8 \%(139)$ & $47.0 \%(71)$ \\
\hline HDL $(\mathrm{M}<40 \mathrm{mg} / \mathrm{dl}, \mathrm{F}<50 \mathrm{mg} / \mathrm{dl})$ & $29.8 \%(128)$ & $30.8 \%(86)$ & $27.8 \%(42)$ \\
\hline $\mathrm{TG}(\geq 150 \mathrm{mg} / \mathrm{dl})$ & $42.3 \%(182)$ & $45.5 \%(127)$ & $36.4 \%(55)$ \\
\hline Glucose $(\geq 100 \mathrm{mg} / \mathrm{dl})$ & $25.3 \%(109)$ & $22.6 \%(63)$ & $30.5 \%(46)$ \\
\hline
\end{tabular}

The prevalence rates of the MetS according to the different definitions in our sample were $28.4 \%$ (ATP-III), $32.3 \%$ (ATP-III A), and 36\% (IDF). The presence of the specific criteria and the number of criteria are shown in Tables 2 and 3.

The MetS was more prevalent in female patients. This difference was mainly explained by more frequent central obesity. Significantly more female patients were obese $(29.1 \%$ obese, $22.5 \%$ overweight $)$ compared to male patients $(14.0 \%$ obese, $42.3 \%$ overweight $)\left(\chi^{2}=22.97, p<.0001\right)$. Female patients were significantly more likely to meet the increased waist criterion according either to ATP-III and ATP-III A $\left(\chi^{2}=30.51, p<.0001\right)$ or IDF $\operatorname{MetS}\left(\chi^{2}=14.43, p<.0001\right)$. 
There was a highly significant effect of age on the prevalence of MetS, regardless of the definition used $(p<.0001, t$-test, respectively, 14.85, 22.01, 30.09). Patients with the MetS were, on average, 5 years older than patients without the MetS. There was no significant difference in the prevalence of MetS between antipsychotic agents in this cross-sectional analysis.

Table 3-Metabolic syndrome and number of criteria prevalence among all subjects

\begin{tabular}{llll}
\hline & All $(N=430)$ & Male $(N=279)$ & Female $(N=151)$ \\
\hline Men age $($ years $)$ & $36.5 \pm 11.8$ & $34.7 \pm 11.3$ & $39.9 \pm 11.6$ \\
Mean BMI $\left(\mathrm{kg} / \mathrm{m}^{2}\right)$ & $26.0 \pm 5.0$ & $25.7 \pm 4.3$ & $26.6 \pm 6.1$
\end{tabular}

\section{Criteria met:}

\begin{tabular}{llll} 
MS ATP-III & $28.4 \%(122)$ & $28.0 \%(78)$ & $29.1 \%(44)$ \\
0 & $24.2 \%$ & $25.8 \%$ & $21.2 \%$ \\
1 & $26.7 \%$ & $27.2 \%$ & $25.8 \%$ \\
2 & $20.7 \%$ & $19.0 \%$ & $23.8 \%$ \\
3 & $15.1 \%$ & $15.0 \%$ & $15.2 \%$ \\
4 & $10.4 \%$ & $11.1 \%$ & $9.3 \%$ \\
5 & $2.8 \%$ & $1.8 \%$ & $4.6 \%$ \\
MS ATP-III A (AHA) & $32.3 \%(139)$ & $30.5 \%(85)$ & $35.8 \%(54)$ \\
0 & $21.9 \%$ & $23.3 \%$ & $19.2 \%$ \\
1 & $24.9 \%$ & $25.4 \%$ & $23.8 \%$ \\
2 & $20.9 \%$ & $20.8 \%$ & $21.2 \%$ \\
3 & $16.3 \%$ & $15.4 \%$ & $17.9 \%$ \\
4 & $12.1 \%$ & $11.8 \%$ & $12.6 \%$ \\
5 & $3.9 \%$ & $3.2 \%$ & $5.3 \%$ \\
MS IDF & $36.0 \%(155)$ & $34.1 \%(95)$ & $39.7 \%(60)$ \\
Waist Additional criteria & $62.1 \%(267)$ & $55.5 \%(155)$ & $74.2 \%(112)$ \\
0 & $24.9 \%$ & $44.3 \%$ & $26.5 \%$ \\
1 & $30.2 \%$ & $55.6 \%$ & $30.5 \%$ \\
2 & $24.2 \%$ & $45.0 \%$ & $23.8 \%$ \\
3 & $15.1 \%$ & $29.8 \%$ & $13.2 \%$ \\
4 & $5.6 \%$ & $9.9 \%$ & $6.0 \%$ \\
\hline
\end{tabular}

Table 4-Relationship between the metabolic syndrome and glucose abnormalities

\begin{tabular}{lllll}
\hline & Normal values & Pre diabetes & Diabetes & Total \\
\hline ATP-III & & & & \\
No & $54.2 \%(233)$ & $16.1 \%(69)$ & $1.4 \%(6)$ & $71.6 \%(308)$ \\
Yes & $12.3 \%(53)$ & $8.8 \%(38)$ & $7.2 \%(31)$ & $28.4 \%(122)$ \\
ATP-III A & & & \\
No & $54.2 \%(233)$ & $12.3 \%(53)$ & $1.2 \%(5)$ & $67.7 \%(291)$ \\
Yes & $12.3 \%(53)$ & $12.6 \%(54)$ & $7.4 \%(32)$ & $32.3 \%(139)$ \\
IDF & & & & \\
No & $51.2 \%(220)$ & $11.4 \%(49)$ & $1.4 \%(6)$ & $64.0 \%(275)$ \\
Yes & $15.4 \%(66)$ & $13.5 \%(58)$ & $7.2 \%(31)$ & $36.0 \%(155)$ \\
Total & $66.5 \%(286)$ & $24.9 \%(107)$ & $8.6 \%(37)$ & \\
\hline & & & &
\end{tabular}

According to ADA criteria $8.6 \%$ of patients met criteria for diabetes, another $24.9 \%$ met criteria for prediabetes ( $20 \%$ IFG, $13.3 \%$ IGT, either isolated or in combination). The prevalence of the metabolic syndrome was significantly higher in diabetic subjects (ATP-III 83.78\%, ATP-III A 86.5\%, IDF 83.78\%) compared to patients with pre diabetic abnormalities (ATP-III 35.1\%, ATP-III A 50.47\%, IDF 54.21\%) and patients without glucose abnormalities (ATP-III 18.53\%, ATP-III A 18.53\%, IDF 23.08\%). Patients with MetS were more likely to meet criteria for diabetes or pre diabetic abnormalities in all definitions of the MetS applied $\left(d f=2\right.$, respectively, $\chi^{2}=$ $75.22,90.59$ and 72.75,p<.0001) (Table 4). 
All parameters evaluated in the OGTT (glucose and insulin values fasting, at $30 \mathrm{~min}$, at $60 \mathrm{~min}$ and $120 \mathrm{~min}$ ) as well as HOMA-IR and glycosylated haemoglobin Alc were significantly different between patients with or without the metabolic syndrome regardless of the definition $(p<.0001)$. All values are higher in patients with MetS. Similar highly significant differences were found on all fasting serum lipid values and calculated lipid risk factors for cardiovascular disease (cholesterol, triglycerides, HDL, LDL, NON-HDL cholesterol, CHOL/HDL and LDL/HDL) $(p<.0001)$.

\section{DISCUSSION}

Our study on the prevalence of MetS in patients diagnosed with schizophrenia is the largest study on a European schizophrenic population as of today. It confirms the high prevalence of MetS in this population, reaching as much as twice the prevalence of the general Belgian population (Rietzschel et al., 2005). The age-adjusted MetS prevalence was $12 \%$ in this community sample and MetS was almost twice as prevalent in male compared to female subjects $(16 \%$ vs. $9 \%)$. Furthermore, the presence of the MetS was associated with an elevated presence of diabetes and cardiovascular risk factors. The prevalence of diabetes in this population is 3 times higher than in the general population. Therefore, these data clearly demonstrate the need for screening for MetS in patients diagnosed with schizophrenia, as suggested by De Nayer et al. (2005) and Marder et al. (2004).

As hypothesized, there was a considerable difference in prevalence rates between our study and the CATIE study. Because our sample consisted of mainly white subjects (99\%), a comparison is best made with the white subject subsample of the CATIE cohort. Hence, the difference remains considerable. Prevalence rates in our sample using ATP-IIIA criteria were $30.5 \%$ for male patients and $35.8 \%$ for female patients, compared to $44.4 \%$ for white male patients and $58.1 \%$ for white female patients in the CATIE study. The explanation for the difference in prevalence rates could well be life style differences in the European vs. the American population. Unfortunately, to our knowledge, no study has specifically handled this issue. Moreover, an important geographical variation of the prevalence rate of MetS within the US population was reported (Ford et al., 2005), further complicating the interpretation of the difference in prevalence rates, especially since our recruitment of patients was restricted to one site. Nevertheless, estimates in the general population have consistently been lower for European than for US populations (Boulogne and Vantyghem, 2004; Ferreira et al., 2005; Ford et al., 2002, 2004; Hu et al, 2004). These findings clearly show the necessity of a careful demographic and symptomatic description and prospective follow-up of different cohorts in distinct areas, in order to determine the influence of life style and genetics to the diagnosis and treatment of MetS.

The current study also has some limitations. First, it is a cross-sectional study. We intent to follow-up this cohort prospectively, in order to assess metabolic changes during the course of the illness and in function of antipsychotic regimes. Second, patient recruitment was restricted to one site, which could have influenced our results, as described above. Third, we failed to include other parameters, such as dietary habits, physical activity level, and schizophrenic and affective symptoms. Future research should address these issues more specifically, in large, multi-site samples and with prospective study designs.

In conclusion, our data confirm the high prevalence of MetS for a European population of patients. Caregivers should carefully monitor and treat metabolic abnormalities in patients diagnosed with schizophrenia.

\section{References}

Allison, D.B., Casey, D.E., 2001. Antipsychotic-induced weight gain: a review of the literature. J. Clin. Psychiatry 62 (Suppl. 7 ), $22-31$.

Allison, D.B., Fontaine, K.R., Heo, M., Mentore, J.L., Cappelleri, J.C., Chandler, L.P., Weiden, P.J., Cheskin, L.J., 1999. The distribution of body mass index among individuals with and without schizophrenia. J. Clin. Psychiatry 60 (4), 215-220.

Basu, R., Brar, J.S., Chengappa, K.N., John, V., Parepally, H., Gershon, S., Schlicht, P., Kupfer, D.J., 2004. The prevalence of the metabolic syndrome in patients with schizoaffective disorder-bipolar subtype. Bipolar Disord. 6 (4), 314-318.

Boulogne, A., Vantyghem, M., 2004. Epidemiological data and screening criteria of the metabolic syndrome. Presse Med. 5 (33(10)), 662665 .

Brown, S., 1997. Excess mortality of schizophrenia. A metaanalysis. Br. J. Psychiatry 171, 502-508.

Brown, S., Inskip, H., Barraclough, B., 2000. Causes of the excess mortality of schizophrenia. Br. J. Psychiatry 177, $212-217$.

Cohn, T., Prud'homme, D., Streiner, D., Kameh, H., Remington, G., 2004. Characterizing coronary heart disease risk in chronic schizophrenia: high prevalence of the metabolic syndrome. Can. J. Psychiatry 49 (11), 753-760. 
Cossrow, N., Falkner, B., 2004. Race/ethnic issues in obesity and obesity-related comorbidities. J. Clin. Endocrinol. Metab. 89 (6), 25902594.

De Hert, M., Van Eyck, D., Hanssens, L., Peuskens, H., Thys, E., Wampers, M., Scheen, A., Peuskens, J., in press. Oral glucose tolerance tests in treated patients with schizophrenia. Data to support an adaptation of the proposed guidelines for monitoring of patients on second generation antipsychotics? Eur. Psychiatr. (Available online).

De Nayer, A., De Hert, M., Scheen, A., Van Gaal, L., Peuskens, J., 2005. Conference report: Belgian consensus on metabolic problems associated with second-generation antipsychotics. Int. J. Psychiatry Clin. Pract. 9 (2), 130-137.

Dixon, L., Postrado, L., Delahanty, J., Fischer, P.J., Lehman, A., 1999. The association of medical comorbidity in schizophrenia with poor physical and mental health. J. Nerv. Ment. Dis. 187 (8), 496-502.

Expert Committee on the Diagnosis and Classification of Diabetes Mellitus, 1997. Report of the expert committee on the diagnosis and classification of diabetes mellitus. Diabetes Care 20, 1183-1197.

Expert Committee on the Diagnosis and Classification of Diabetes Mellitus, 2003. Follow-up report on the diagnosis of diabetes mellitus. Diabetes Care 26, 3160-3166.

Expert Panel on Detection and Evaluation of Treatment of High Blood Cholesterol in Adults, 2001. Executive summary of the third report of the National Cholesterol Education Program (NCEP) expert panel on detection, evaluation and treatment of high blood cholesterol in adults (Adult Treatment Panel III). JAMA 285, 2486-2497.

Ferreira, I., Twisk, J.W., van Mechelen, W., Kemper, H.C., Stehouwer, CD., 2005. Development of fatness, fitness, and lifestyle from adolescence to the age of 36 years: determinants of the metabolic syndrome in young adults: the Amsterdam growth and health longitudinal study. Arch. Intern. Med. 165 (1), 42-48.

Ford, E.S., Giles, W.H., Dietz, W.H., 2002. Prevalence of the metabolic syndrome among US adults: findings from the third National Health and Nutrition Examination Survey. JAMA 287 (3), 356-359.

Ford, E.S., Giles, W.H., Mokdad, A.H., 2004. Increasing prevalence of the metabolic syndrome among U.S. adults. Diabetes Care 27 (10), 2444-2449.

Ford, E.S., Mokdad, AH., Giles, W.H., Galuska, D.A., Serdula, M.K., 2005. Geographic variation in the prevalence of obesity, diabetes, and obesity-related behaviors. Obes. Res. 13 (1), 118-122.

Grundy, S.M., Cleeman, J.I., Merz, C.N., Brewer, H.B., Clark, L.T., Hunninghake, D.B., Pasternak, R.C., Smith, S.C., Stone, N.J., 2004 Implications of recent clinical trials for the National Cholesterol Education Program Adult Treatment Panel III guidelines. Circulation 110 (2), 227-239

Haupt, D.W., Newcomer, J.W., 2001. Hyperglycemia and antipsychotic medications. J. Clin. Psychiatry 62 (Suppl. 27), 15-26 (discussion 40-1).

Heiskanen, T, Niskanen, L., Lyytikainen, R., Saarinen, P.L, Hintikka, J., 2003. Metabolic syndrome in patients with schizophrenia. J. Clin Psychiatry 64 (5), 575-579.

Homel, P., Casey, D., Allison, D.B., 2002. Changes in body mass index for individuals with and without schizophrenia, $1987-1996$. Schizophr. Res. 55 (3), 277-284.

Hu, G, Qiao, Q., Tuomilehto, J., Balkau, B., Borch-Johnsen, K., Pyorala, K., 2004. Prevalence of the metabolic syndrome and its relation to all-cause and cardiovascular mortality in nondiabetic European men and women. Arch. Intern. Med. 164 (10), $1066-1076$.

IDF, 2005. The IDF Consensus Worldwide Definition of the Metabolic Syndrome. Brussels, International Diabetes Federation (online).

Jin, H., Meyer, J.M, Jeste, D.V., 2002. Phenomenology of and risk factors for new-onset diabetes mellitus and diabetic ketoacidosis associated with atypical antipsychotics: an analysis of 45 published cases. Ann. Clin. Psychiatry 14 (1), 59-64.

Jin, H., Meyer, J.M., Jeste, D.V., 2004. Atypical antipsychotics and glucose dysregulation: a systematic review. Schizophr. Res. 71 (2-3), 195-212.

Kraja, A., Rao, D., Weder, A., Mosley, T, Turner, S., Hsiung, C, Quertermous, T, Cooper, R., Curb, J.D., Province, M., 2005. An evaluation of the metabolic syndrome in a large multi-ethnic study: the Family Blood Pressure Program. Nutr. Metab. 2 (1), 17.

Lyketsos, C.G, Dunn, G, Kaminsky, M.J., Breakey, W.R., 2002. Medical comorbidity in psychiatric inpatients: relation to clinical outcomes and hospital length of stay. Psychosomatics 43 (1), 24-30.

Marder, S.R., Essock, S.M., Miller, A.L., Buchanan, R.W., Casey, D.E., Davis, J.M., Kane, J.M., Lieberman, J.A., Schooler, N.R., Covell, N, Stroup, S., Weissman, E.M., Wirshing, D.A., Hall, C.S., Pogach, L., Pi-Sunyer, X., Bigger, J.T., Friedman, A., Kleinberg, D., Yevich, S.J., Davis, B., Shon, S., 2004. Physical health monitoring of patients with schizophrenia. Am. J. Psychiatry 161 (8), 1334-1349. 
McEvoy, J.P., Meyer, J.M., Goff, D.C., Nasrallah, H.A., Davis, S.M., Sullivan, L., Meltzer, H.Y., Hsiao, J., Scott Stroup, T, Lieberman, J.A., 2005. Prevalence of the metabolic syndrome in patients with schizophrenia: baseline results from the Clinical Antipsychotic Trials of Intervention Effectiveness (CATIE) schizophrenia trial and comparison with national estimates from NHANES III. Schizophr. Res. 80 (1), $19-32$.

Meduna, L., Gerty, F., Urse, V., 1942. Biochemical disturbances in mental disorders. Arch. Neurol. Psychiatry (47), $38-52$.

Meyer, J.M., Koro, C.E., 2004. The effects of antipsychotic therapy on serum lipids: a comprehensive review. Schizophr. Res. 70 (1), 1-17.

Meyer, J.M., Nasrallah, H.A., McEvoy, J.P, Goff, D.C., Davis, S.M., Chakos, M., Patel, J.K., Keefe, R.S.E., Scott Stroup, T, Lieberman, J.A., 2005. Prevalence of the metabolic syndrome in patients with schizophrenia: baseline results from the Clinical Antipsychotic Trials of Intervention Effectiveness (CATIE) schizophrenia trial and comparison with national estimates from NHANES III. Schizophr. Res. 80 (1), 918

Misra, A., Wasir, J.S., Vikram, N.K., 2005. Waist circumference criteria for the diagnosis of abdominal obesity are not applicable uniformly to all populations and ethnic groups. Nutrition $21(9), 969-976$

Newcomer, J.W., 2005. Second-generation (atypical) antipsychotics and metabolic effects: a comprehensive literature review. CNS Drugs 19 (Suppl. 1), 1-93.

Osby, U, Correia, N, Brandt, L., Ekbom, A, Sparen, P., 2000. Mortality and causes of death in schizophrenia in Stockholm county, Sweden. Schizophr. Res. 45 (1-2), 21-28.

Osby, U, Correia, N, Brandt, L., Ekbom, A, Sparen, P., 2000. Time trends in schizophrenia mortality in Stockholm county, Sweden: cohort study. BMJ 321 (7259), 483-484.

Park, Y.W., Zhu, S., Palaniappan, L., Heshka, S., Carnethon, M.R., Heymsfield, S.B., 2003. The metabolic syndrome: prevalence and associated risk factor findings in the US population from the Third National Health and Nutrition Examination Survey, 1988-1994. Arch. Intern. Med. 163 (4), 427-436.

Rakugi, H., Ogihara, T, 2005. The metabolic syndrome in the Asian population. Curr. Hypertens. Rep. 7 (2), $103-109$.

Raphael, T.P., 1921. Blood sugar studies in dementia praecox and manic depressive insanity. Arch. Neurol. Psychiatry 5,687-709.

Rietzschel, E., De Buyzere, M., De Bacquer, D., Langlois, M., Bekaert, S., De Backer, G., Gillebert, T., 2005. Metabolic syndrome, a map of the cardiovascular damage. Results from the asklepios study in 2528 apparently healthy 35-55 year old subjects. Abstracts Conference European Society of Cardiology. Eur. Heart J. 26, 110.

Robinson, D.G., Woerner, M.G, Alvir, J.M., Bilder, R.M., Hinrich-sen, G.A., Lieberman, J.A., 2002. Predictors of medication discontinuation by patients with first-episode schizophrenia and schizoaffective disorder. Schizophr. Res. 57 (2-3), 209-219.

Scheen, A.J., De Hert, M., 2005. Drug-induced diabetes mellitus: the example of atypical antipsychotics. Rev. Med. Liege 60 (5-6), 455-460.

Weiden, P.J., Mackell, J.A., McDonnell, D.D., 2004. Obesity as a risk factor for antipsychotic noncompliance. Schizophr. Res. 66 (1), $51-57$. 